American Journal of

Health, Medicine and Nursing Practice (AJHMN)

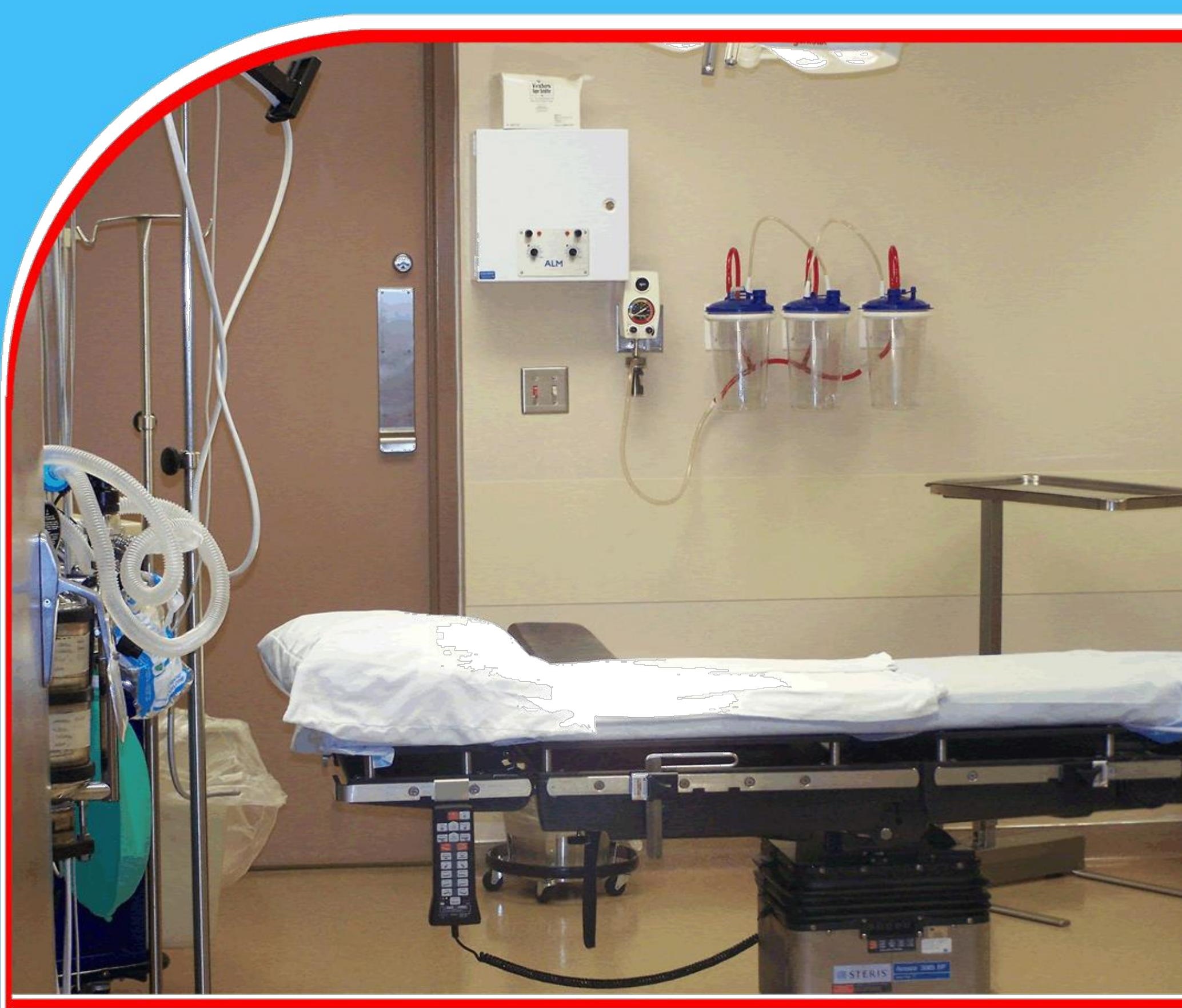

THE EFFECT OF INFORMATION AND COMMUNICATION TECHNOLOGY ON FINANCIAL MANAGEMENT SYSTEM EFFECTIVENESS IN HEALTH ORIENTED CIVIL SOCIETY ORGANIZATIONS

Carolyne Wambui and Amos Njuguna

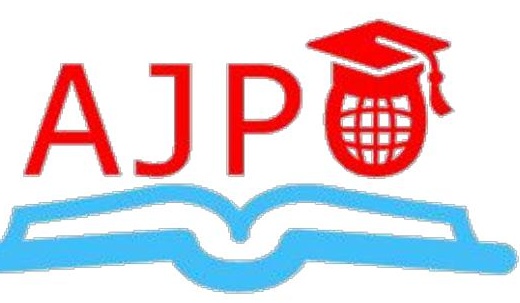




\title{
THE EFFECT OF INFORMATION AND COMMUNICATION TECHNOLOGY ON FINANCIAL MANAGEMENT SYSTEM EFFECTIVENESS IN HEALTH ORIENTED CIVIL SOCIETY ORGANIZATIONS
}

\author{
${ }^{1 *}$ Carolyne Wambui \\ ${ }^{1 *}$ Post Graduate Student \\ United States International University \\ *Corresponding Author's Email: wambui.carol@gmail.com \\ ${ }^{2}$ Amos Njuguna \\ Dean, Chandaria School of Business
}

\begin{abstract}
Purpose: The purpose of this study was to determine the extent to which Information and Communication technology affects the financial management system effectiveness in health oriented civil society organizations.

Methodology: The study was conducted through a cross sectional descriptive survey. The target population of the study was 1065 Nongovernmental organizations in Kenya. The accessible population refers to the 606 Nongovernmental organizations located in Nairobi County. A sample of $10 \%$ equivalent to 61 Nongovernmental organizations was selected from the Nongovernmental organizations located in Nairobi County. The respondents were financial managers in every selected Nongovernmental organization. Data was collected by use of a questionnaire and was analyzed by use of inferential and descriptive statistics. Descriptive statistics included frequencies and means. Inferential statistics included correlation, regression and ANOVA analysis. The tool for data analysis was the Statistical Package for Social Sciences (SPSS) version 20. The results were presented using tables and pie charts.

Results: The study results indicated that information technology management in nongovernmental organizations are reliable and flexible enough to support the financial management of the organization. Additional results indicated that Nongovernmental organizations had invested in a management information system which had lowered administrative costs. The usage of IT led to efficient management of processes of budget accounting. The findings imply that information technology has significant positive effect on financial management system

Unique contribution to theory, practice and policy: The study provided recommendations to the NGOs and other organization that ICT development should be maximized fully in the organization especially if the objective is to improve efficiency and financial management systems effectiveness.
\end{abstract}

Keywords: information and communication technology, financial management system, health oriented civil society organization 


\subsection{INTRODUCTION}

\subsection{Background of the Study}

Good financial management is a key to an organizational sustainability as it impacts decision making across the organization and as such should be integrated into all aspects of an organization's operations, from managing project budgets to gathering information for strategic decision-making. Nonprofit voluntary organization must practice sound financial management and comply with a diverse array of legal and regulatory requirements (Liljander and Strandvik, 2010). Whatever the size of the organization, sound financial strategy is a prerequisite to sustainability, rather than being seen as a separate function (merely doing book keeping), the finance should be integrated within, and add value to, the overall planning and management of an organization. It is essential that organizations successfully manage their funding and financing sources to ensure the best and most efficient use of their financial resources (Liljander and Strandvik, 2010).

The financial management processes of not for- profit organizations are generally dominated by conditions of resource scarcity. Such organizations have limited opportunities for generating additional income, but are faced with an ever increasing agenda of programme and activities on which such funds could be spent (Drucker, 2000). Sustainable funding means being able to be there for your beneficiaries in the long term. An organization is financially sustainable if its core work will not collapse if its external funding is withdrawn.

An effective financial management system improves short and long term business performance by streamlining invoicing and bill collection, eliminating accounting errors, minimizing record-keeping redundancy, ensuring compliance with tax and accounting regulations, helping personnel to quantify budget planning, and offering flexibility and expandability to accommodate change and growth (Ogara and Gitoho, 2005). Leaders and managers of NGOs have to develop, at the very least, basic skills in financial management. Basic skills in financial management start in the critical areas of cash management and bookkeeping, which should be carried out following certain financial controls to ensure integrity in the bookkeeping process (Liljander and Strandvik, 2010). New leaders and managers should swiftly learn how to generate financial statements and analyze those statements so as to develop a real understanding of the financial condition of the organization. Financial analysis shows the 'reality' of the situation of an organization and as such, is one of the most important practices in management (Liljander and Strandvik, 2010) Organizations are required to use funds wisely for the purpose intended and improve the living standards of the populations meant to benefit. Often, uses of funds are diverted to serve other interests of the organization managers outside the scope and work plans of these projects (Liljander and Strandvik, 2010). This has resulted in surprise audits where misuses of funds are suspected by donors and in the extreme cases bank accounts have been frozen to minimize the extent (Ogara and Gitoho, 2005).Good management practices demand that obvious key management concepts and principles such as sustainability, accountability and transparency which are necessary for institutionalized formal procedures are put in place (Ogara and Gitoho, 2005). Most donors attach various restrictions to their funding including among others-sound financial management systems in place, good leadership with integrity, educated staff with and the strategic plans of the organization. NGOs lacking these ingredients have difficulties attracting donor funding (Ogara and Gitoho, 2005).

Sustainability is the core of organizational effectiveness and connected to all other key components (WCC, 2005). Sustainable strategies must therefore be considered in the areas of strategic direction, moral values, governance, management practices, human resources, and impact of service delivery, financial resources and external relations (WCC, 2005). 
Sustainable organizations have been found to have at a minimum: A clear mission and strategic direction, the necessary skills to attract resources from a variety of local and international sources, skills and ability to manage resources effectively and efficiently and any effort at organizational regeneration (Ogara and Gitoho, 2005).

A core activity in organizations is the management of financial resources with various accounting cycles of the accounting operation. These cycles initiate financial transaction processing, whose outcomes contribute to the operational, tactical and strategic decisions in organizations. Extended reviews on accounting information systems (AIS) research (Ferguson and Seow, 2011; Poston and Grabski, 2000) provide theories, designs, and categories of AIS research. While there has been coverage of broad topics in AIS research, an important issue of fit of AIS to an organization in a dynamic business environment has not received resolute attention. Past research in information systems has defined system effectiveness in terms of "user information satisfaction" or perceptions of system users about the extent to which the information system available to them meets their information requirements (Nicolaou, 2000).

In general, the NGOs focus on different components needed to achieve their objectives. Health based NGOs provide the communities with the ability, knowledge and confidence to demand the health services they need. The NGOs also partner with national, regional and local health authorities to ensure health benefits to Kenyan citizens. They work together in taking care of infected persons through providing medication and advising on proper nutrition to ensure longevity (Waweru, 2010). NGOs assist those in the health sector to meet its mandate. The mandate of the health sector (hospitals, clinics and dispensaries) is to deliver heath services to its customers taking into consideration the returns to shareholders as well as its role in sustainable development of the community. This mandate is outlined in both the Millennium Development Goals and Vision 2030: to reduce child mortality by two-thirds (MDG 4); reduce maternal mortality by three-quarters (MDG 5); halt and begin to reverse the spread of HIV/AIDS (MDG 6); halt and begin to reverse the incidence of malaria and other major diseases (MDG 6). However, according to Samantha (2011), the penetration of all levels of healthcare service delivery in Kenya is poor which points a finger at both the NGOs and the other or profit institutions operating in the health sector.

\subsection{Problem Statement}

Experience reveals that the financial management processes of NGOs are generally weak and dominated by conditions of resource scarcity vis-à-vis the ever increasing agenda of social development activities on which such funds could be spent (Samantha, 2011). Sustainable funding has helped many NGO's implement diverse programmatic interventions which has not only benefited the communities but has also improved the standard of living. But tough economic times buoyed by global recession have in one way or another affected global funding. Many NGOs continue to cease operations by the day often due to lack of sustainable funding. Many new others are also set-up any day it dawns leaving one with question marks rather than answers as to what's ailing the sector. Many new NGOs fall into the pitfall of unsustainability, as they operate for a summer or for a few years and then fade away (Waweru, 2010).

The voluntary organization should ensure that annual budgets are approved by the board, its financial system is reliable and all the financial records (accounts) are kept in time. The organizations should assure the financial resources are used in furtherance of the organization's charitable purposes. In order to establish sound governance practices we have to establish an effective structure of overall and financial management. For every voluntary organization and its members it is very much important to understand the basic concept of 
financial term; budgeting, financial strategy, accounting system, financial policy, social security for its staffs, internal control \& internal audit (Samantha, 2011).

Several studies on financial management systems effectiveness of NGOs have been conducted. These studies include, Magezi (2010), who focused on the relationship between governance and quality of financial reports in NGOs. However, this study did not focus on health NGOs in Kenya. Wamai (2004) conducted a study on the comparative trends in transforming health care systems in Kenya and Finland by focusing on NGO and public health care systems. However, the study failed to address the concept of financial management systems effectiveness of health oriented civil society organizations in Kenya. Kameri-Mbote (2000) conducted a study on the operational environmental and constraints for NGOs in Kenya. However, the study mainly concentrated on the regulatory regime and failed to discuss how NGOs employ financial management systems. Other studies that addressed NGOs are Marete (2007), Mudanya (2007), Odongo (2008), Wairimu (2008), Ombok (2009), Njihia (2009), Keziah (2010), Mutua (2010). Nonetheless, the studies failed to address financial management systems effectiveness of NGOs in the Kenyan health sector. The main research gap stems from the scarcity of studies on this area and the failure of the qualitative factors affecting the financial management systems effectiveness of health oriented civil society organization in Kenya. The study therefore sought to bridge this knowledge gap by assessing the factors affecting the financial management systems effectiveness of health oriented civil society organization in Kenya.

\subsection{Research Objective}

The main objective of this study is to determine the extent to which information and Communication technology affect the financial management system effectiveness in health oriented civil society organizations.

\subsection{LITERATURE REVIEW}

\subsection{Empirical Review}

Generally, there is little investment in ICT for health in most developing countries. The picture is one of fragmentation, with many different varieties of ICT being acquired from different donors. Invariably, there is no national health information and IT infrastructure to underpin the delivery of health care. It is very important to make a realistic financial plan for all the costs in the system before the introduction of the HMIS (Gladwin et al. 2003).

Information technology has changed the performance of traditional accounting systems. Increasingly more information, which is produced in electronic form, must be processed, stored and presented in information technology based accounting systems. Dominant processes of globalization and ambient in which modern systems of budget accounting function, as a basic subject of public finances, have led to new requirements and needs for improvement of process of management and decision making in accordance with the requirements from the environment and developed concepts of modern information communication technologies (Gladwin et al. 2003). In order to have efficient management of processes of budget accounting, it is necessary to improve the process of decision making and managing, by providing consistent information and by developing information system that generates processes and distributes that information. Process of management and decision making requires quality, effectiveness, efficiency, and integration of processes, consistency and concurrent approach to data (Heidmann, 2008).

A system is an organized way of completing tasks. An information system (IS) is a combination of information technology (IT), people, procedures, and data to manage the processes and activities of an organization (Turban and Volonino, 2011). That is, an 
information system is a systemic way of capturing and processing data by people using some form of IT. Thus, an effective information system is one that is the best model of the events of the reality, and is able to mimic the events and procedures of the real world (Turban and Volonino, 2011).

The accounting environment of the real world is complicated, which presents great challenges to system developers to develop AIS to capture the events and activities of the real business environment. Some form of structure is present with rigid and established frameworks and standards like the generally accepted accounting principles (GAAP) for transaction processing and financial reporting. However, financial opportunism owing to agency relationships (Jensen and Meckling, 1976), rationalization for fraud owing to current economic times (Romney and Steinbart, 2011), and the complex nature of business transactions means AIS face constant threats of being maneuvered to manage activities that are not consistent with the expectations of the real world. This situation means that internal controls associated with an AIS needs constant evaluation and reconsideration. These elements that surround AIS requires the AIS to be dynamic and part of a dynamic environment, with the capacity for swift reorganization in events of maneuvering threats.

A number of health information technologies (IT) assist clinicians in providing efficient, quality care. However, just as health IT can offer potential benefits, it can also interrupt workflow, cause delays, and introduce errors (Kaushal, 2003). Health IT evaluation is difficult and complex because it is often intended to serve multiple functions and is conducted from the perspective of a variety of disciplines. Lack of attention to health IT evaluation may result in an inability to achieve system efficiency, effectiveness, and satisfaction (Kaushal, 2003). Consequences may include frustrated users, decreased efficiency coupled with increased cost, disruptions in workflow, and increases in healthcare errors (Kaushal, 2003).

Health information technology, through the implementation of computerized provider order entry with clinical decision support, has been increasingly identified as a means to improve medication safety. These systems are also expected to produce substantial reductions in healthcare costs. Individualized medication ordering recommendations for long-term care residents with varying levels of renal function is an ideal application of a clinical decision support system (CDSS), as renal impairment is common in this setting. For example, in a study of residents of 83 long-term care facilities in Ontario, Canada, among those aged 75 or older, it was determined that nearly a third had estimated creatinine clearances of $<30$ $\mathrm{ml} / \mathrm{min}$. Papaioannou et al.(2001) have reported results from a cross-sectional study of nursing home residents indicating that $40 \%$ had an inappropriate prescription for a drug based on creatinine clearance. This finding underscores the importance of this issue as a public health concern with policy implications (Kaushal, 2003).

To provide optimal care, healthcare institutions need timely patient information from various sources at the point-of-care, and need a comprehensive, complete and fully functional system to fulfill all these needs. One way to achieve this is through the use of ICT in health care. ICT is defined in this research as a tool that facilitates communication, the processing and transmission of information and the sharing of knowledge by electronic means. This encompasses the full range of electronic digital and analogue ICT, from radio and television to telephones (fixed and mobile), computers, electronic-based media such as digital text and audio-video recording, and the Internet, but excludes the non-electronic technologies. However this does not lessen the importance of non-electronic technologies such as paper- 
based text for sharing information and knowledge or communicating about health (WHO, 2004).

The development of man must start from a common ground which can be disease and illnesses (WHO, 2004). From the clinical understanding of illness, its successful diagnosis or the practice of medicine itself, technology has become omnipresent in the field. In the practice of development, the intersection of ICTs and health is commonly called e-health (WHO, 2007). It is essentially the use of ICTs in medicine for knowledge management and service delivery, a combination which can improve the delivery of medical services and can by consequence improve health outcomes. The World Health Organization (WHO, 2007) determined that there are five essential components to e-health which are: Structural enhancement in the delivery of health services; Engagement with stakeholders and the private sector in improving the availability and appropriateness of technologies; Learning how to use the technological tools; Creation of standardized norms and practices and; Evaluation and monitoring of the application and impact of ICTs to health (WHO, 2007).

IT could serve NGOs in different ways; it could improve productivity, increase the overall effectiveness through better collaboration, and extend services to new communities in need. Moreover, IT can be a powerful force that opens exciting opportunities for NGOs to achieve their missions and goals in an effective way. Therefore, leaders in NGOs must obtain an overall appreciation of the potential of IT and link the acquisition and utilization of IT to the organizational mission. The impact of IT on NGOs services and performance has been examined by many studies. Although most of these studies have suggested that IT plays a vital role in improving the quality and quantity of information, its potential for adoption and innovation is often uncertain (Mano, 2009).

According to Mullins (2005), the main approaches that have dominated ICT implementation theory include: Technological determinism: This is a technology driven approach that focuses mainly on the application of available technologies to organizational set ups through the use of appropriate methodological tools. Socio-technical interactions: This is a bottom-up approach that deals with the interaction between structures of the technology and the social structures of the organization and with the emergent effects arising from such interaction. Socio-economic Shaping of Technology (SST). Mullins (2005) also states that the focus of SST is upon the ways in which technology is shaped by (rather than itself shaping) the economic, technical, political and social circumstances in which it is designed, developed and utilized. 4) Social Construction of Technology (SCT) views technology as emerging out of non rational-linear process of invention, design, development and innovation. 5) Actor Network Analysis (ANA) is an approach for describing and explaining social, organizational, scientific and technological structures, processes and events. It assumes that all the component of such structures form a network of relations that can be mapped and described in the same terms or vocabulary. Organizational Imperative: This is a strategic top-down approach that creates links between business objectives, business strategy and ICT strategies and implementation.

The pervasiveness of ICT has brought about rapid teleological, social, political and economic transformation, which has eventuated in a network society organized around ICT (Yusuf, 2005). The author posited that ICT is an indispensable part of educational administration as its application makes institutions more efficient and productive, thereby engendering a variety of tools to enhance and facilitate teachers' pedagogical activities. For instance, elearning is becoming one of the most common means of using ICT to provide education to students both on and off campus by means of teaching online offered via web-based systems. 
A response to a humanitarian aid operation is characterized by a large number of unrelated organizations descending simultaneously on a given location. To operate safely and successfully carryout their mission, NGOs not only need to receive information from a wide variety of sources, but also must provide information to others as well (Yusuf, 2005). Ensuring both the internal and the external flow of such information depends on an NGO's ICT infrastructure. Hundreds of NGOs throughout the world focus on emergency relief operations. Most NGOs use some type of technology to manage information and communications in what are often remote, chaotic, and unsafe areas (Yusuf, 2005). The types of technology used in a relief scenario are generally dictated by the phase of the emergency, type of mission, remoteness of the location, availability of network infrastructure, and the internal capacity and capabilities of the NGO to use the technology (Yusuf, 2005).

\subsection{RESEARCH METHODOLOGY}

The study was conducted through a cross sectional descriptive survey. The target population of the study was NGOs working in the health sector in Kenya. The study focused on 1065 NGOs. From the 1065 NGOs, 606 NGOs are located in Nairobi. This formed the accessible population. The unit of analysis was the financial manager of each NGO as he/she was more conversant with the information that was being sought. The sampling frame was retrieved from the NGO Coordination Board website and this was up to date by 30 December, 2012. Simple random sampling was used. The NGOs were listed on a piece of paper and the papers were folded and 61 papers picked without replacement. However, the $10 \%$ would yield 61 NGOs, a figure that was not too large or too small considering the logistics and the economic resources at the disposal of the researcher. The study used a questionnaire as the preferred data collection tool. The study used the quantitative method of data analysis. Quantitative methods of data analysis include inferential and descriptive statistics. The rationale for using quantitative methods for data analysis was because some of the data results required quantitative interpretation. Inferential statistics included regression modeling, and correlation analysis. The tool for data analysis was Statistical Package for Social Sciences (SPSS) version 20 program. The results were presented using tables and pie charts to give a clear picture of the research findings.

\subsection{RESULTS AND DISCUSSIONS}

\subsection{Response Rate}

All questionnaires (61) that were distributed were received for data analysis.

\subsection{Demographic Characteristics}

\subsubsection{Gender of Respondents}

The study sought to establish the gender of respondents of NGOs operation. Gender of respondents is important since it may influence financial management system effectiveness. The respondents were requested to indicate their gender. $(54.1 \%)$ of the respondents were male while the rest, $45.9 \%$ were female. The results indicate that the finance department was a male dominant field. The results are in Figure 1. 


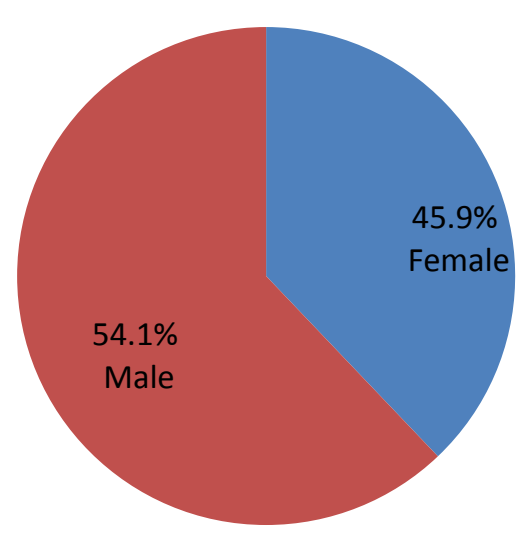

Figure 1: Gender of Respondents

\subsubsection{Level of Education}

The study sought to establish the level of education of respondents of NGOs operation. Level of education is important since it may influence financial management system effectiveness. The respondents were requested to indicate their level of education. Results indicate that $(49.2 \%)$ of the respondents indicated that their highest level of academic qualification was university level. (21.3\%) indicated that their highest level of academic achievement was college while a further $(29.5 \%)$ were post graduate. The findings implied that the employees in NGOs are highly qualified and this may have a positive implication on the level of financial management system effectiveness. These results are shown in Table 1.

\section{1: Level of Education}

\begin{tabular}{|l|c|c|}
\hline Education Level & Frequency & Percent \\
\hline College & 13 & 21.3 \\
\hline University & 30 & 49.2 \\
\hline Postgraduate & 18 & 29.5 \\
\hline Total & 61 & 100 \\
\hline
\end{tabular}

\subsubsection{Period Employed}

The study sought to establish the period employed in NGOs operation. Period of employment is important since it may influence financial management system effectiveness. The respondents were asked to indicate their period of employment. (41\%) of the respondents indicated that they had been working between 2 to 5 years. A further $(31 \%)$ has been working in the NGOs for 6 to 10 years, $(10 \%)$ for 11 to 15 years while $(22 \%)$ have been working in the NGOs for 10 and above years and $(21.3 \%)$ have been working for over 10 years while (6.6\%) had been employed in the NGOs sector for less than one year. The findings imply that the employee set consists of employees of varying experience. The results are in Figure 2. 


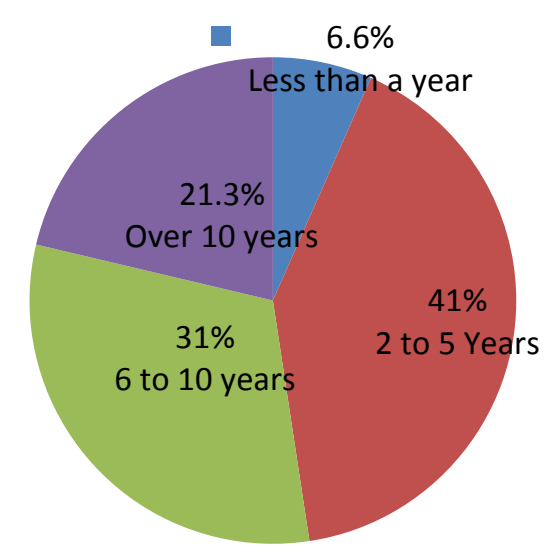

Figure 2: Period Employed

\subsubsection{NGO Years of Operation}

The study sought to establish the NGOs years of operation. NGOs years of operation are important since it may influence financial management system effectiveness. The results on the years of operation of the NGO are presented in Table 2. The majority of the respondents indicated that majority of the registered NGO's in Kenya have been operating for over 10 years and between 6 to 10 years as represented by $(42.6 \%)$ and $(36.1 \%)$ respectively. Few NGO's have operations between 2 to 5 years as indicated by a percent of (19.7\%). The results are shown in Table 4.2.The findings implied that majority of the NGOs had been in operation for a long time therefore the findings were reliable.

Table 2: Age of NGO

\begin{tabular}{|l|c|c|}
\hline Period of NGO Operation & Frequency & Percent \\
\hline Less than 1 year & 1 & 1.6 \\
\hline 2 to5 years & 12 & 19.7 \\
\hline 6 to 10 years & 22 & 36.1 \\
\hline Over 10 years & 26 & 42.6 \\
\hline Total & $\mathbf{6 1}$ & $\mathbf{1 0 0}$ \\
\hline
\end{tabular}

\subsubsection{Scope of NGO's Operation}

The study sought to establish the scope of NGOs operation. Scope of NGOs operation is important since it may influence financial management system effectiveness. Results in Figure 3 shows that majority of the NGO's in Kenya have operations locally as indicated by (54\%), while those operating at a regional extent are at (38\%). Eight percent (8\%) represent the NGO's whose operation is at an international level. This implied that there are many running NGOs locally based to help the poor communities. 


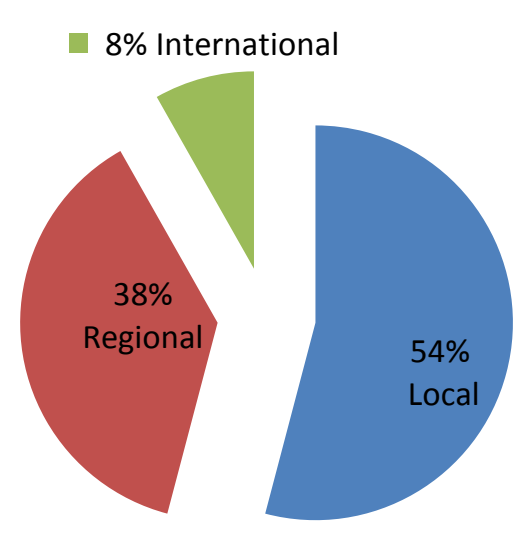

\section{Figure 3: Scope of NGO}

\subsubsection{NGOs' Sources of Funding}

The study sought to establish the NGOs' sources of funding. NGOs' sources of funding are important since it may influence financial management system effectiveness. Sources of funding for the majority of the NGO's in Kenya is through donors as represented by $(87 \%)$ while $(13 \%)$ shows that some of the funding from some NGO's is received from the local community. The results of this finding are represented in Figure 4.The findings imply that most running NGOs are supported by the donor to accomplish their mission.

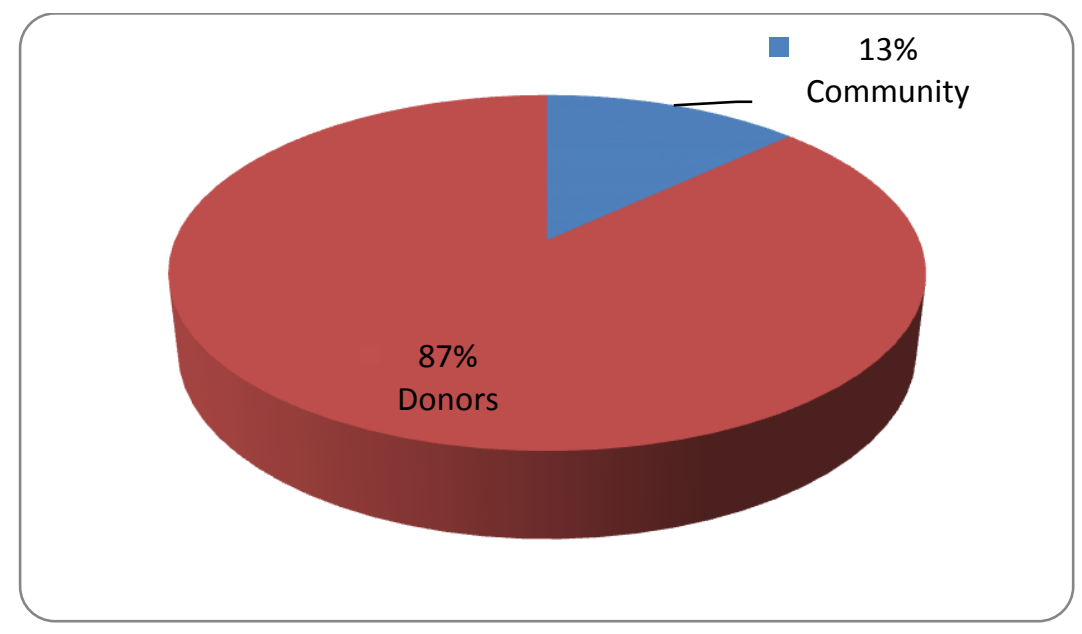

\section{Figure 4: Sources of funds}

\subsection{Descriptive Statistics}

\subsubsection{Reliability of the Organizations' Management Information Systems}

The respondents were asked if the management system of the organization was reliable. Reliability of the organization financial management may influence financial management system effectiveness. A majority of them (60.7\%) agreed and (1.6\%) strongly agreed bringing to a total of $(62.3 \%)$ of those who agreed. Thirteen point one percent $(13.1 \%)$ 
disagreed and (3.3\%) strongly disagreed while (21.3\%) were neutral. The results are presented in table 3.

Table 3: Reliability of the Organizations Management Information Systems

\begin{tabular}{|l|c|c|c|}
\hline Statement & Scale & Frequency & Percentage \\
\hline $\begin{array}{l}\text { Management information system of the } \\
\text { organization is reliable }\end{array}$ & Strongly Disagree & 2 & $3.30 \%$ \\
\cline { 2 - 4 } & Disagree & 8 & $13.10 \%$ \\
\cline { 2 - 4 } & Neutral & 13 & $21.30 \%$ \\
\cline { 2 - 4 } & Agree & 37 & $60.70 \%$ \\
\cline { 2 - 4 } & Strongly agree & 1 & $1.60 \%$ \\
\hline
\end{tabular}

\subsubsection{Flexibility of the Management Information Systems}

The respondents were asked if the management information system was flexible enough to supports the financial management of the organization. Flexibility of the organization financial management may influence financial management system effectiveness. Majority $(62.3 \%)$ agreed and $(4.9 \%)$ strongly agreed bringing to a total of $(67.2 \%)$ of those who agreed with the statement. Sixteen point four percent $(16.4 \%)$ disagreed, while (14.8\%) were neutral and $(1.6 \%)$ strongly disagreed. The results are presented in table 4.

\section{Table 4: Flexibility of Management Information Systems}

\begin{tabular}{|l|c|c|c|}
\hline Statement & Scale & Frequency & Percentage \\
\hline $\begin{array}{l}\text { The management information system is } \\
\text { flexible enough to supports the financial } \\
\text { management of the organization }\end{array}$ & Strongly Disagree & 1 & $1.60 \%$ \\
\cline { 2 - 4 } & Disagree & 10 & $16.40 \%$ \\
\cline { 2 - 4 } & Neutral & 9 & $14.80 \%$ \\
\cline { 2 - 4 } & Agree & 38 & $62.30 \%$ \\
\cline { 2 - 4 } & Strongly agree & 3 & $4.90 \%$ \\
\hline
\end{tabular}

\subsubsection{Investment of Management Information System Enables Administrative Costs}

The respondents were asked if the investment of management information system enabled administrative costs. Fifty two point five percent $(52.50 \%)$ were agreeing and $(3.30 \%)$ strongly agreeing bringing to a total of $(55.80 \%)$ of those who agreed with the statement. The result further show that $(26.20 \%)$ were neutral to the statement with $(16.40 \%)$ relatively disagreeing. One point six percent $(1.60 \%)$ strongly disagreed that the organization has invested in a management information system which has enabled administrative costs. 
Table 5: Investment of Management Information System Enables Administrative Costs

\begin{tabular}{|l|c|c|c|}
\hline Statement & Scale & Frequency & Percentage \\
\hline $\begin{array}{l}\text { The organization has invested in a } \\
\text { management information system which } \\
\text { has enabled administrative costs }\end{array}$ & Strongly Disagree & 1 & $1.60 \%$ \\
\cline { 2 - 4 } & Disagree & 10 & $16.40 \%$ \\
\cline { 2 - 4 } & Neutral & 16 & $26.20 \%$ \\
\cline { 2 - 4 } & Agree & 32 & $52.50 \%$ \\
\cline { 2 - 4 } & Strongly agree & 2 & $3.30 \%$ \\
\hline
\end{tabular}

\subsubsection{The MIS of the Organization Enhances Performance and Productivity}

The respondents were asked if the management information systems of the Organization enhanced performance and productivity. (55.70\%) strongly agreed and (8.20\%) agreed responses bringing to a total of $(63.9 \%)$ of those who agreed. The responses neutral to the statement were at $(21.30 \%)$, with (11.50\%) disagreeing and (3.30\%) strongly disagreed responses.

Table 6: The MIS of the Organization Enhances Performance and Productivity

\begin{tabular}{|l|c|c|c|}
\hline Statement & Scale & Frequency & Percentage \\
\hline $\begin{array}{l}\text { The management information system } \\
\text { of the organization has been crucial in } \\
\text { assisting financial management staff } \\
\text { to enhance their performance and } \\
\text { productivity }\end{array}$ & Strongly Disagree & 2 & \\
& & & $3.30 \%$ \\
\cline { 2 - 4 } & Disagree & 7 & $11.50 \%$ \\
\cline { 2 - 4 } & Neutral & 13 & $21.30 \%$ \\
\cline { 2 - 4 } & Agree & 34 & $55.70 \%$ \\
\cline { 2 - 4 } & Strongly agree & 5 & $8.20 \%$ \\
\hline
\end{tabular}

\subsubsection{Complete and Fully Functional System}

The respondents were asked if the financial management information system has enhanced complete and fully functional system. Financial management information system the organization financial management may influence financial management system effectiveness. Results in Table 7 indicate that (52.5\%) agreeing and (6.60\%) strongly agreeing needs thus bringing to a total of $(67.2 \%)$ of those who agreed that financial management information has contributed to fully functional systems that fulfill organizations'. This was further received with $(24.6 \%)$ moderately agreeing to the statement with $(13.10 \%)$ and $(3.30 \%)$ disagreeing and strongly disagreeing to the statement. 
Table 7: Financial Management Information Has Enhanced Complete and Fully Functional Systems to Fulfill Organization Needs

\begin{tabular}{|c|c|c|c|}
\hline Statement & Scale & Frequency & Percentage \\
\hline \multirow{5}{*}{$\begin{array}{l}\text { The Financial management information } \\
\text { system has enhanced complete and fully } \\
\text { functional system to fulfill all organization } \\
\text { needs }\end{array}$} & Strongly Disagree & 2 & $3.30 \%$ \\
\hline & Disagree & 8 & $13.10 \%$ \\
\hline & Neutral & 15 & $24.60 \%$ \\
\hline & Agree & 32 & $52.50 \%$ \\
\hline & Strongly agree & 4 & $6.60 \%$ \\
\hline
\end{tabular}

\subsubsection{Efficiency in Budgeting Process through Financial Management Information Systems}

The respondents were asked if the financial management information system has led to efficient management of processes of budget accounting. Efficiency in budgeting process of the organization financial management may influence financial management system effectiveness. From the results in Table 8 responses received (59\%) and (14.80\%) agreed and strongly agreed respectively that MIS has led to efficient management of budget accounting processes. Further, $(14.80 \%)$ of the responses received were neutral to the statement with $(1.60 \%)$ and $(9.80 \%)$ response rate not supporting that financial management information system has led to efficient management of processes of budget accounting.

Table 8: Efficiency in Budgeting Process through Financial Management Information Systems

\begin{tabular}{|c|c|c|c|}
\hline Statement & Scale & Frequency & Percentage \\
\hline \multirow{5}{*}{$\begin{array}{l}\text { The financial management information } \\
\text { system has led to efficient management of } \\
\text { processes of budget accounting }\end{array}$} & Strongly Disagree & 1 & $1.60 \%$ \\
\hline & Disagree & 6 & $9.80 \%$ \\
\hline & Neutral & 9 & $14.80 \%$ \\
\hline & Agree & 36 & $59.00 \%$ \\
\hline & Strongly agree & 9 & $14.80 \%$ \\
\hline
\end{tabular}

Results reveal that majority of NGOs had implemented information and communication technology measures. This has resulted to the reliability of management information system of the organization, flexibility of management information system, investment in a management information system in an organization, administrative costs of the organization, staff financial management in an organization, complete and fully functional system and efficient management of processes of budget accounting in an organization.

\subsection{DISCUSSION CONCLUSIONS AND RECOMMENDATIONS}

\subsection{Discussion}

The objective of the study was to determine the effect of Information and Communication Technology on financial management systems. Results indicated that majority of the respondents agreed with the statements that management system of the organization was reliable. The findings agree with those in Turban and Volonino (2011) who asserted that a system is an organized way of completing tasks. An information system (IS) is a combination of information technology (IT), people, procedures, and data to manage the processes and 
activities of an organization (Turban and Volonino, 2011). That is, an information system is a systemic way of capturing and processing data by people using some form of IT. Thus, an effective information system is one that is the best model of the events of the reality, and is able to mimic the events and procedures of the real world.

Results also show that the financial management information system has led to efficient management of processes of budget accounting and that the system of the organization has been crucial in assisting financial management staff to enhance their performance and productivity. These results support those of Yusuf (2005) who posited that ICT is an indispensable part of educational administration as its application makes institutions more efficient and productive, thereby engendering a variety of tools to enhance and facilitate teachers' pedagogical activities.

Results show that the majority agreed with the statement that the organization has invested in a management information system which has enabled administrative cost. The findings agree with those of Kaushal (2003) who noted that a number of health information technologies (IT) assist clinicians in providing efficient, quality care. However, just as health IT can offer potential benefits, it can also interrupt workflow, cause delays, and introduce errors (Kaushal, 2003). Health IT evaluation is difficult and complex because it is often intended to serve multiple functions and is conducted from the perspective of a variety of disciplines. Lack of attention to health IT evaluation may result in an inability to achieve system efficiency, effectiveness, and satisfaction (Kaushal, 2003).Consequences may include frustrated users, decreased efficiency coupled with increased cost, disruptions in workflow, and increases in healthcare errors.

Results also show that majority agreed with the statement that management information systems in managing staff performance and productivity. The findings are consistent with those of Mano (2009) who found out that IT could serve NGOs in different ways; it could improve productivity, increase the overall effectiveness through better collaboration, and extend services to new communities in need. Moreover, IT can be a powerful force that opens exciting opportunities for NGOs to achieve their missions and goals in an effective way. Therefore, leaders in NGOs must obtain an overall appreciation of the potential of IT and link the acquisition and utilization of IT to the organizational mission. The impact of IT on NGOs' services and performance has been examined by many studies. Although most of these studies have suggested that IT plays a vital role in improving the quality and quantity of information, its potential for adoption and innovation is often uncertain.

Results also show that financial management information has contributed to fully functional systems that fulfill organizations. The findings agree with those of Kaushal (2003) who noted that a number of health information technologies (IT) assist clinicians in providing efficient, quality care. However, just as health IT can offer potential benefits, it can also interrupt workflow, cause delays, and introduce errors. Health IT evaluation is difficult and complex because it is often intended to serve multiple functions and is conducted from the perspective of a variety of disciplines. Lack of attention to health IT evaluation may result in an inability to achieve system efficiency, effectiveness, and satisfaction (Kaushal, 2003). Consequences may include frustrated users, decreased efficiency coupled with increased cost, disruptions in workflow, and increases in healthcare errors.

Study results also show that the financial management information system has led to efficient management of processes of budget accounting. The findings agree with those of Heidmann,(2008) who found out that information technology has changed the performance of traditional accounting systems. Increasingly more information, which is produced in electronic form, must be processed, stored and represented in information technology based 
accounting systems. Dominant processes of globalization and ambient in which modern systems of budget accounting function, as a basic subject of public finances, have led to new requirements and needs for improvement of process of management and decision making in accordance with the requirements from the environment and developed concepts of modern information communication technologies (Heidmann,2008). In order to have efficient management of processes of budget accounting, it is necessary to improve the process of decision making and managing, by providing consistent information and by developing information system that generates processes and distributes that information (Heidmann, 2008). Process of management and decision making requires quality, effectiveness, efficiency, and integration of processes, consistency and concurrent approach to data (Heidmann, 2008).

\subsection{Conclusions}

Findings led to conclusions that information technology management in NGO's was reliable and flexible enough to support the financial management of the organization. It was possible to conclude that the management information system of the organization had been crucial in assisting financial management staff to enhance their performance and productivity. Additional results concluded that NGOs had invested in a management information system which had enabled administrative costs.

The study also led to conclusions that Health IT can offer potential benefits like reducing delays as it is intended to serve multiple functions. This will lead to ability to achieve system efficiency, effectiveness, and satisfaction.

The study results led to conclusions that health information technology, through the implementation of computerized provider order entry with clinical decision support, has been increasingly identified as a means to improve medication safety as these systems are also expected to produce substantial reductions in healthcare costs.

\subsection{Recommendations}

The study provides recommendation to the NGO and other organization that ICT development should be maximized fully in the organization especially if the objective is to improve efficiency and financial management systems effectiveness.

\subsection{Areas for Further Studies}

A replica study could be done on a governmental institution and the survey results would be used for comparative analysis between nongovernmental institutions and governmental, (public) institutions. Further studies could also include other factors such availability of resources, leadership or culture of the organization and the rules and regulations of the financial governing bodies or local authorities that affects the effectiveness of financial management systems in companies.

\section{REFERENCES}

Ferguson, C., and Seow,P. S. (2011). Accounting information systems research over the past decade: Past and future trends, Accounting \& Finance, 51, 235-251.

Heidmann, M., Schaffer, U., \& Strahringer, S. (2008). Exploring the Role of Management Accounting Systems in Strategic Sense making. Information Systems Management, 25(3), 244-257.

Kameri-Mbote, P. (2000). The Operational Environment and Constraints for NGOs in Kenya: Strategies for Good Policy and Development. Switzerland: International Environmental House. 
Kaushal R, Shojania KG, Bates DW. (2003). Effects of computerized physician order entry and clinical decision support systems on medication safety: a systematic review. Arch Intern Med 2003;163:1409e16.

Keziah, M. (2010). The Strategic Responses Adopted by KPA to Changing External Environment. University of Nairobi: Unpublished MBA Project.

Mano.R.S. (2009). Information technology, adaption and innovation in nonprofit human service organizations. Journal of Technology in Human Services, 27(3), p227-234.

Mareta, N.C. (2007). The Strategic Response of Glaxosmithkline Pharmaceuticals towards competition in Kenya.Unpublished MBA Thesis. University of Nairobi

Mudanya, S. M. (2007). Response Strategies to Environmental Challenges to firms in the Cement Industry in Kenya. University of Nairobi: Unpublished MBA Project.

Mutua, C.K. (2010). Strategic Responses by the Deposit Protection Fund Board to Changes in the External Environment. University of Nairobi: Unpublished MBA Project.

Nicolaou, A. I. (2000). A contingency model of perceived effectiveness in accounting information systems: Organizational coordination \& control effects. International Journal of Accounting Information Systems 1(2): 91-105, [Online] Available:http://www.sciencedirect.com/science/article/B6W6B-416BX86.

Njihia, N.N. (2009). Strategic Responses of Kenya Commercial Bank Limited to Changes in Kenyan Banking Industry. University of Nairobi: Unpublished MBA Project.

Odongo, T.O. (2008). Strategic Responses by Kenya Tourist Development Corporation to Changes in its Environment. University of Nairobi: Unpublished MBA Project.

Ogara, W. (2005). Church Financial Sustainability. Catholic University of Eastern Africa

Ombok, F.S.A. (2009). Response Strategies of International Non-governmental Organizations in Nairobi to Changes in the Macro Environment. University of Nairobi: Unpublished MBA Project

Papaioannou A, Ray J.G., Ferko N.C. (2001). Estimation of creatinine clearance in elderly persons in long-term care facilities. Am J Med 2001;111:569e73.

Poston, R. and Grabski,S. (2000).Accounting information systems research: Is it another qwerty. International Journal of Accounting Information Systems, 1, 9-53.

Romney, M. B., and Steinbart P. J. (2011). Accounting infromation systems. (Pearson).

Turban, E,.and VoloninoL. (2011). Information technology for management. (Wiley).

Wamai, G.R. (2004). NGO and Public Health Systems: Comparative Trends in Transforming Health Care Systems in Kenya and Finland. Researcher. University of Helsinki, Finland. Department of Social Policy/Institute of Development Studies. 